Удк 655.3.066.51

( ) Н. Є. Кулішова, к.т.н., професор, А. А. Попова, Харківський національний університет радіоелектроніки, Харків, Украйна

\title{
ПОБУДОВА НЕЧІТКИХ ОЦІНОК СПОТВОРЕНИХ ЗОБРАЖЕНЬ
}

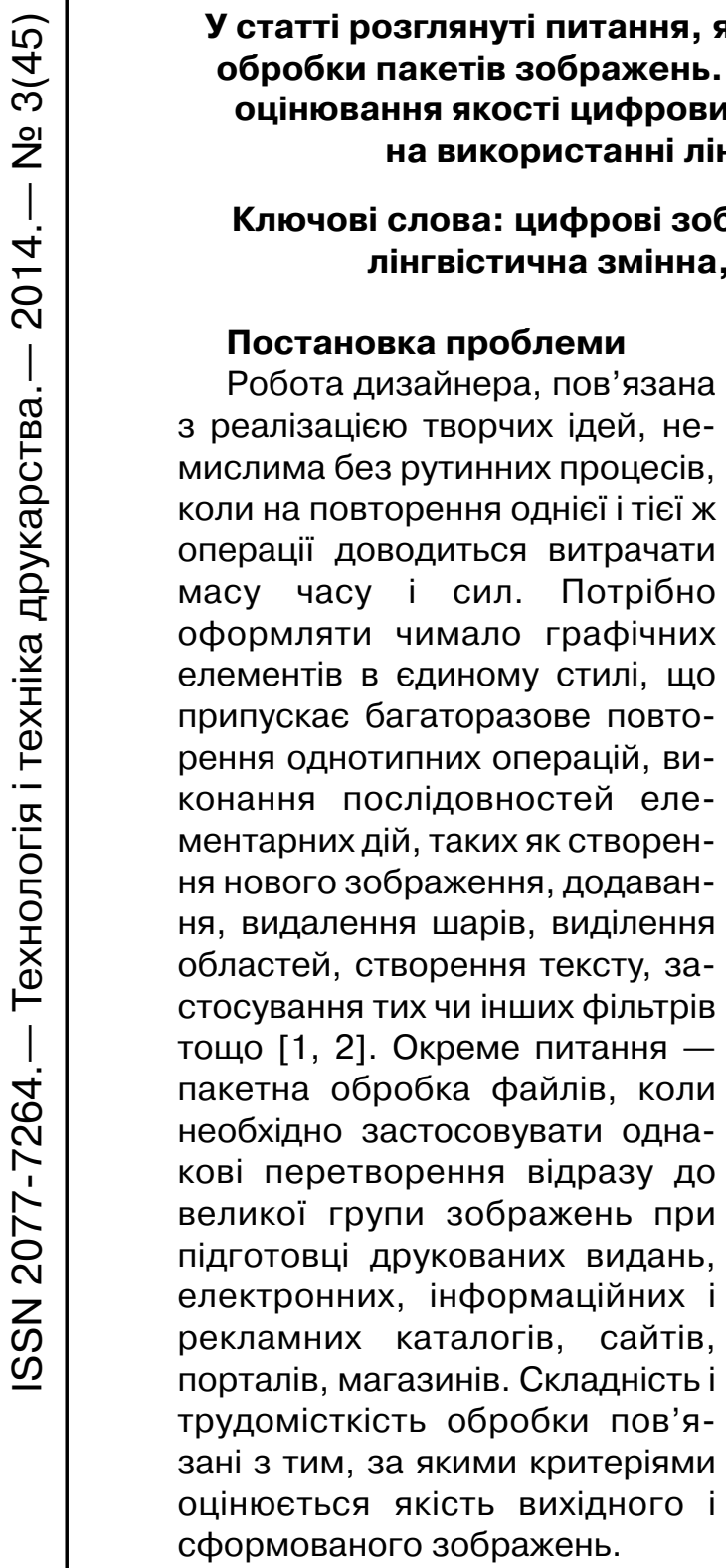

(C) $2014 \mathrm{p}$.
Якість такого складного об'єкта як зображення є дуже важливим, але водночас і досить нечітким поняттям. Іноді якість розглядається як характеристика самого зображення і визначається його властивостями (статистичними, структурними, семантичними). Хоча цифрова обробка зображень будується на основі математичних та імовірнісних формулювань, людська інтуїція і аналіз відіграють центральну роль при виборі того чи іншого методу серед усіх, і цей вибір часто реалізується на основі суб'єктивного візуального оцінювання. Кожна людина сприймає інформацію суб'єктивно, і по-різному бачить одне й те ж зображення $[3,4]$.

Найбільшого поширення набув метод оцінок, при якому спостерігач оцінює якість зображення в балах за певною шкалою. Методика суб'єктивних вимірів зазвичай регламентує випробувальні зображення, спостерігача-дизайнера, шкали 
оцінок, умови спостереження, порядок проведення вимірювань, ранжування зображень щодо результатів.

Суб'єктивність сприйняття ускладнює застосування формалізованого підходу. Тому при обробці зображень набули поширення методи, в яких часто відсутні суворі математичні критерії оптимальності. Їх замінюють якісні уявлення про доцільність тієї чи іншої обробки, які спираються на суб'єктивні оцінки результатів [5].

\section{Мета роботи}

Метою даної роботи є створення формального способу оцінювання ступеня зашумленості і спотворень зображення, що дозволить скоротити час обробки великої кількості оригіналів з подібними характеристиками.

Об'єктом дослідження є процедура редакторської обробки оригіналів на етапі редакційновидавничої підготовки. Предмет - методи визначення статистичних характеристик зображень, методи формування лінгвістичних оцінок, методи нечіткого оцінювання.

\section{Аналіз попередніх досліджень}

Для вирішення завдання оцінки зображення в загальному вигляді потрібно знайти кількісні оцінки, які найкращим чином відповідають суб'єктивним.

Один з підходів перетворення суб'єктивної думки експерта в математичні об'єктивні дані був запропонований Л. Заде, він пов'язаний 3 введенням лінгвістичних змінних, що описують неточне (нечітке) відображення людиною навколишнього світу [6].

Лінгвістична змінна приймає значення 3 множини слів або словосполучень деякої природної або штучної мови. Поняття лінгвістичної змінної складається з набору [7]:

$$
\langle A, T(A), U, V, M\rangle \text {, }
$$

де $A$ - назва змінної; $\mathrm{T}(\mathrm{A})$ терм-множини змінної $A$, тобто множина назв лінгвістичних значень змінної A, причому кожне 3 таких значень - нечітка змінна із значеннями з універсальної множини U; V - синтаксичне правило, яке породжує назви значень лінгвістичної змінної $A$; М - семантичне правило, яке ставить у відповідність кожній нечіткій змінній з Т(A) нечітку підмножину універсальної множини U.

У звичайній теорії множин існує кілька способів завдання множини. Одним з них є завдання за допомогою характеристичної функції. Нечіткі множини $€$ природним узагальненням звичайних множин, оскільки характеристична функція може приймати будь-які значення 3 відрізка [0, 1]. Більш строго, нечіткою множиною А називається сукупність пар $\mathrm{x} \in \mathrm{U}\{(\mathrm{mA}(\mathrm{x}))\}$, де $\mathrm{mA}$ - функція приналежності: mA:U[0,1]. За відсутності статистики вважають, що функції приналежності або інформація для їх побудови задаються експертами на основі суб'єктивних переваг і не 


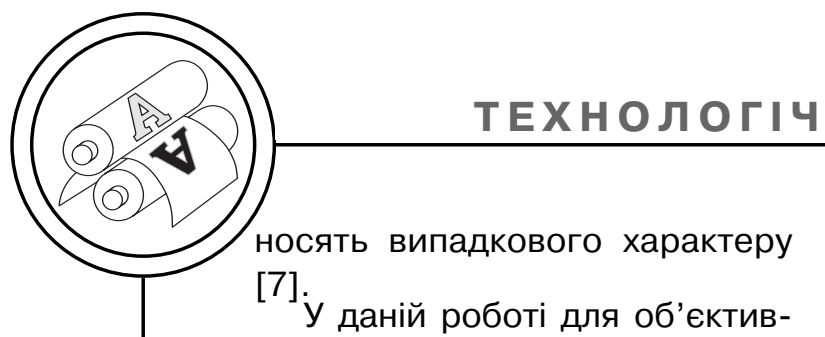

персійному коефіцієнті конкордації:

$$
\mathrm{K}_{\mathrm{w}}=\frac{12 \mathrm{~S}}{\mathrm{r}^{2}\left(\mathrm{n}^{3}-\mathrm{n}\right)},
$$

фектів на зображеннях та їх ранжування на основі лінгвістичних змінних пропонується використовувати кількісні оцінки рівня шуму і нерізкості цифрового зображення. Цифровий шум - дефект зображення, що вноситься фотосенсором і електронікою пристроїв, які їх використовують (цифровий фотоапарат, теле/відеокамери тощо). Він виглядає як світлі, темні або різнокольорові точки, що заповнюють цілі області кадру.

Шум складається $з$ двох частин: варіацій кольору і яскравості. Шум яскравості на зображенні проявляється у вигляді маленьких темних точок, нагадуючи зерно аналогових фотоплівок. Хроматичний шум виділяється на зображенні у вигляді різнокольорових точок, які за кольором відмінні від кольору області, на якій вони з'являються [8].

Різкість зображення можна визначити як чіткість кордонів між областями різної яскравості або як ступінь контрасту на контурах.

В основу методу входить побудова функцій приналежності $\mathrm{mA}$ для кожного з двох дефектів. Функції приналежності будуються на основі статистичної інформації, за участю групи експертів [9].

Для побудови функції приналежності формуються групові оцінки ступеня приналежності, які повинні бути узгодженими. Оцінка узгодженості думок експертів заснована на дис-

де S - сума квадратів відхилень суми рангів кожного об'єкта експертизи від середнього арифметичного рангів; $r$ - кількість експертів; $\mathrm{n}$ - кількість об'єктів експертизи. Коефіцієнт конкордації може мати значення від нуля до одиниці (для повної згоди). При $\mathrm{K}_{\mathrm{w}}=1-$ повна узгодженість, при $\mathrm{K}_{\mathrm{w}}=0-$ узгодженість відсутня, при $\mathrm{K}_{\mathrm{w}}>0,7$ - достатня [9].

\section{Результати проведених досліджень}

Для експериментальної перевірки ефективності даного способу формального опису дефектів був зібраний комплект 3 100 тестових зображень 3 різним ступенем наявності на них шуму і нерізкості. Кожне 3 зображень - це результат зйомки на цифрову фотокамеру в різних умовах: денна, нічна зйомка, зйомка пейзажна або певного об'єкта, в приміщенні, на вулиці, при штучному і природному освітленні [10].

Для отримання лінгвістичної змінної було запрошено 5 експертів, які ранжирували зображення за 4 категоріями за рівнем шуму і розмиття. Попередня оцінка зводиться до ранжирування оригіналів. Типи зображень утворюють такі терми T(A) лінгвістичної змінної $A$ «рівень зашумленості зображення»:

- «дуже шумне зображення» - значно помітний шум в 
світлах, тінях, зображення спотворюється через утворену поверх «маску з різнокольорових пікселів»;

- «середньо шумне зображення» - сильні шуми, значно погіршують якість зображення. Велика кількість тіней сприяє появі зашумлених ділянок, однак не може служити виправданням кінцевого результату. Погано зчитуються деталі в світлі і тінях через досить помітний рівень шуму;

- «слабо шумне зображення» - на об'єктах темні шуми не помітні, проте в тіньових областях і на тлі шуми вже видно, це не дуже добре, але цілком припустимо;

- «нешумне зображення» шуми практично не помітні: ані на моделі і предметах, ані навіть на однорідно-градієнтних областях сірого фону.
Для кількісної оцінки рівня шуму і формування значень універсальної множини U [11] зображення було переведено в чорно-біле і виконаний розрахунок дисперсії [12]:

$$
\begin{aligned}
& \sigma=\sqrt{\frac{\pi}{2}} \times \frac{1}{6(\mathrm{~W}-2)(\mathrm{H}-2)} \times \\
& \times \sum_{\text {imagei }}|\mathrm{I}(\mathrm{x}, \mathrm{y}) \mathrm{N}|
\end{aligned}
$$

де W, H - ширина і висота зоб-

раження, $N=\left[\begin{array}{ccc}1 & -2 & 1 \\ -2 & 4 & -2 \\ 1 & -2 & 1\end{array}\right]$ - опе-

ратор Лапласа. Перевагою цього цього методу $є$ використання згортки з лапласіаном, який нечутливий до структури зображення, а значення згортки залежать тільки від шуму в зображенні.

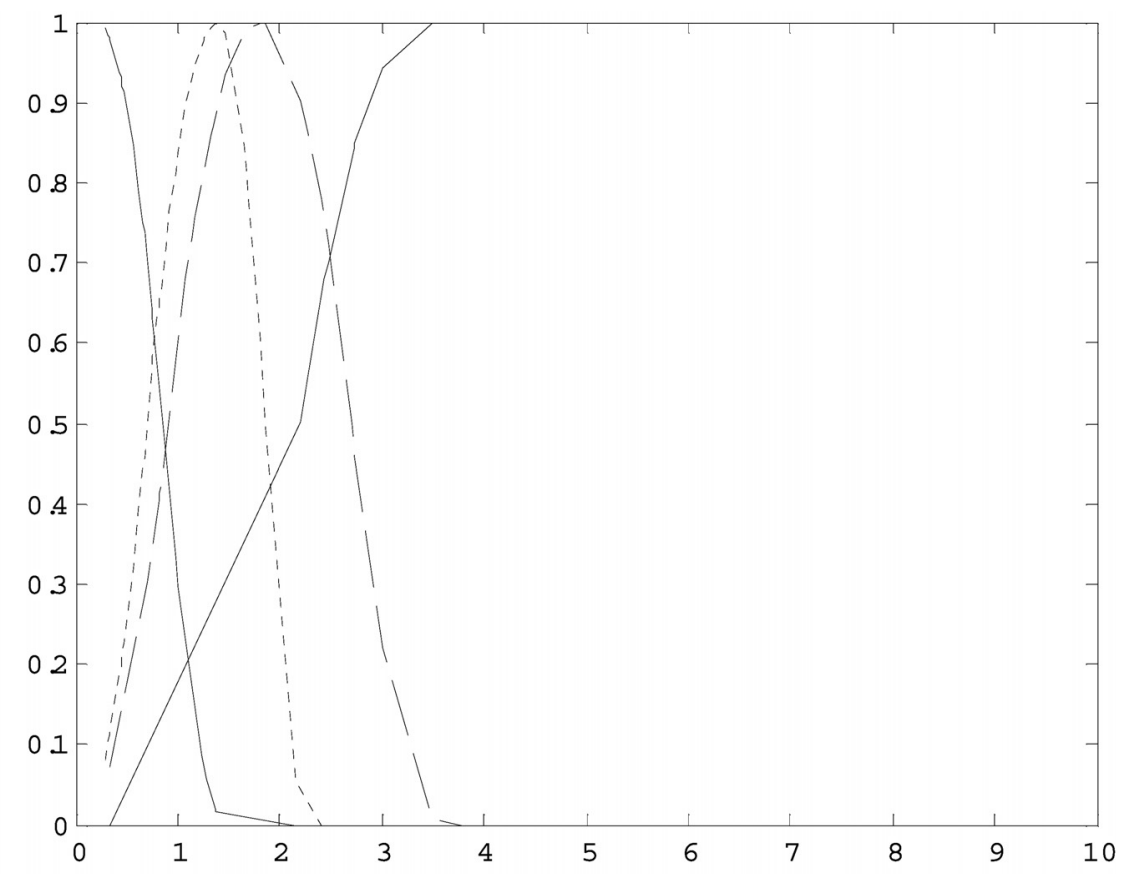

Рис. 1. Графіки функцій приналежності для шумних зображень 
На основі цих результатів виведені залежності ступеня впевненості в суб'єктивній оцінці від рівня шуму на зображенні, побудовані графіки функції приналежності зображень до певної нечіткої множини (рис. 1).

Кожному терму відповідає певний діапазон значень рівня шуму, i, відповідно, за цими даними можна ранжувати потрібну кількість зображень для наступної обробки. Спеціалізований математичний пакет виконує розподіл вихідного набору тестових зображень за розрахованою дисперсією, її граничними значеннями є такі: «дуже шумне» від 2,2 і вище, «середньо шумне» від 1,65 до 2,2; «слабо шумне» від 0,8 до 1,65; «нешумне» від 0 до 0,8. Для терма «нешумне» зображення функція приналежності має вигляд:

$$
=\left\{\begin{array}{cc}
f(x ; a, b)= \\
1, & x \leq a \\
1-2\left(\frac{x-a}{b-a}\right)^{2}, & a \leq x \leq \frac{a+b}{2} \\
2\left(\frac{x-a}{b-a}\right)^{2}, & \frac{a+b}{2} \leq x \leq b \\
0, & x \geq b
\end{array}\right\} ;
$$

для терма «дуже шумне»:

$$
\left\{\begin{array}{cc}
f(x ; a, b)= \\
2\left(\frac{x-a}{b-a}\right)^{2}, & a \leq x \leq \frac{a+b}{2} \\
1-2\left(\frac{x-a}{b-a}\right)^{2}, & \frac{a+b}{2} \leq x \leq b \\
1, & x \geq b
\end{array}\right\}
$$

для термів «середньо шумне» і «слабо шумне»:

$$
\left\{\begin{array}{cc}
f(x ; a, b)= \\
2\left(\frac{x-a}{b-a}\right)^{2}, & a \leq x \leq \frac{a+b}{2} \\
1-2\left(\frac{x-b}{b-a}\right)^{2}, & \frac{a+b}{2} \leq x \leq b \\
1, & b \leq x \leq c \\
1-2\left(\frac{x-c}{d-c}\right)^{2}, & c \leq x \leq \frac{c+d}{2} \\
2\left(\frac{x-d}{d-c}\right)^{2}, & \frac{c+d}{2} \leq x \leq d \\
0, & x \geq d
\end{array}\right\} .
$$

Оскільки графіки приналежності для слабо і середньошумних зображень дуже близькі, вони були замінені одним термом - «середньо шумне» 3 П-подібною функцією приналежності (6). Була також виконана їх апроксимація (рис. 2), щоб забезпечити одиничне розбиття Руспіні, тобто виконання умови

$$
\sum_{i=1}^{n} \mu_{i}(x)=1 \text {. }
$$

В роботі також виконано ранжування зображень за рівнем розмиття. Попередня оцінка зводиться до сортування оригіналів в такі групи:

- «дуже розмите зображення» - зображення дуже каламутне, дрібні деталі взагалі не простежуються, погана передача кольору;

- «середньо розмите зображення» - дуже помітне змазування «розмилювання», контури об'єктів розмиті, різкість досить низька. Автофокус об'єктива промахнувся або не встиг за об'єктом. В результаті чіткими виявилися другорядні деталі 


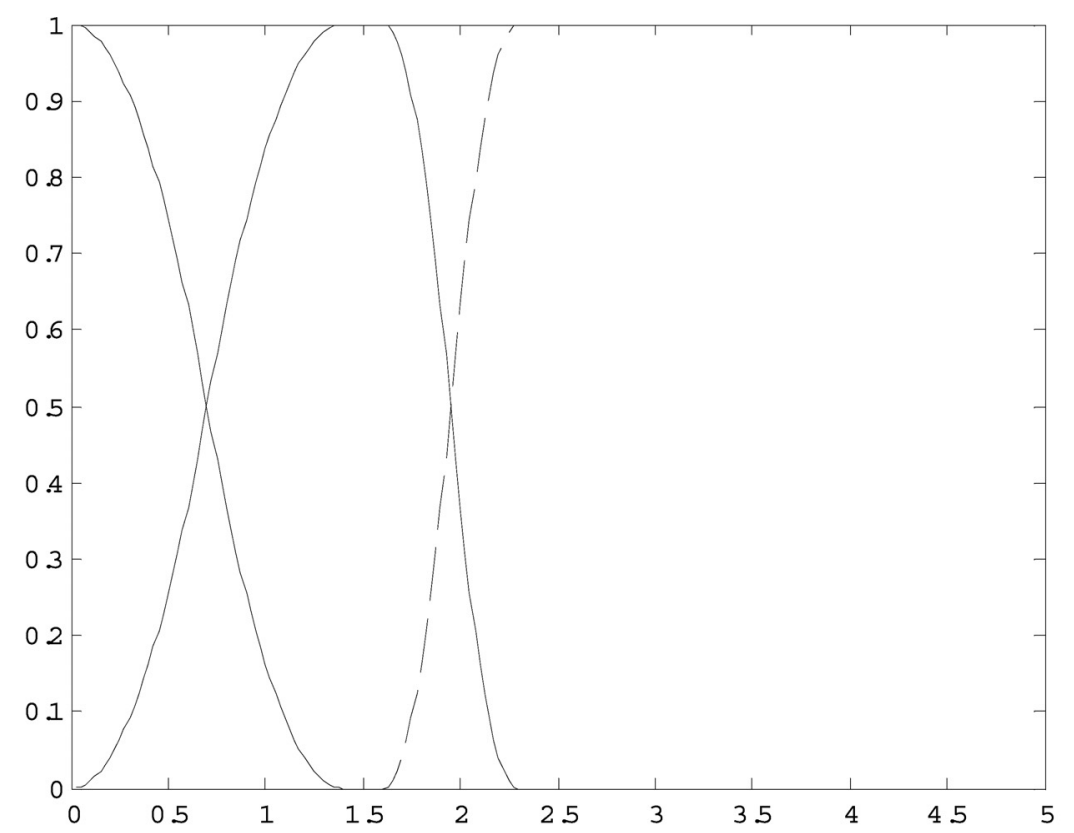

Рис. 2. Графіки функцій приналежності для шумних зображень після апроксимації

фону, подібна якість не припустима;

- «слабо розмите зображення» - на темних об'єктах спотворення непомітні, проте змазування або розфокусування вже видно, але це можна переплутати 3 великим збільшенням при зйомці. Фотографія зроблена на широко відкритій діафрагмі, тому глибина різкості дуже мала, значна частина зображення розмита, якщо дивитися на 100 \% масштабі. Проте частина зображення потрапила в різкість, створивши граючий контраст між розмитими і чіткими частинами, це цілком прийнятна якість;

- «нерозмите зображення» - зображення, яке не має спотворень в кольорі, а також досить різке, деталі в світлі і тінях чітко окреслені. Об'єктив зфокусова- ний в потрібну точку, як результат зображення з хорошою деталізацією.

Чисельно оцінити ступінь розмиття можна, обчислюючи різницю між сусідніми пікселями до і після низькочастотної фільтрації зображення [13].

Як і для шуму, для розмиття були побудовані графіки функцій належності (рис. 3).

Спеціалізований математичний пакет, за аналогією з шумом, виконує розподіл набору тестових зображень за групами, граничними значеннями оцінок розмиття $є$ : «дуже розмите» від 0,45 і вище (функція приналежності виду (5)), «середньо розмите» від 0,3 до 0,45; «слабо розмите» від 0, 15 до 0,3 (функції приналежності виду (6)); «нерозмиті» від 0 до 0,15 (функція приналежності виду (4)). Для 


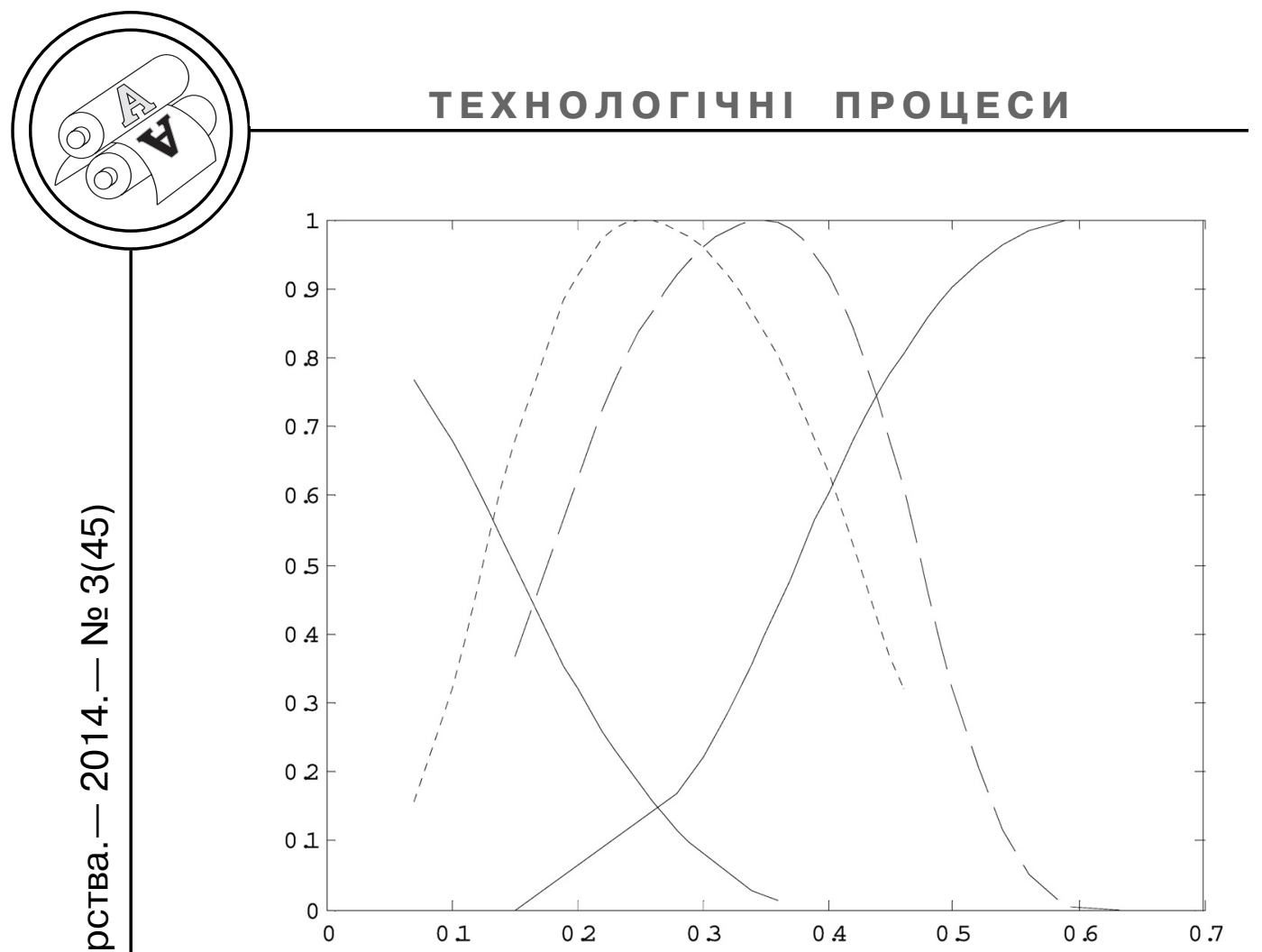

Рис. 3. Графіки функцій приналежності для розмитих зображень

цієї змінної також були об'єднані два терма - «середньо розмите» і «слабо розмите» в терм «середньо розмите зображення», і виконана апроксимація для забезпечення розбиття Руспіні (рис. 4).

Для перевірки узгодженості та компетентності експертів за результатами оцінювання п'яти різних зображень було зроблено розрахунок коефіцієнта конкордації (2):

$$
\begin{aligned}
& K_{w}=\frac{12 S}{r^{2}\left(n^{3}-n\right)}=\frac{12 \cdot 8}{25 \cdot 6}+ \\
& +\frac{12 \cdot 8}{25 \cdot 6}+\frac{12 \cdot 18}{25 \cdot 6}+\frac{12 \cdot 4,5}{25 \cdot 6}+ \\
& +\frac{12 \cdot 4,5}{25 \cdot 6}=0,68 \approx 0,7,
\end{aligned}
$$

що підтвердило добру узгодженість думок експертів.

\section{Висновки}

В даній роботі розглянуто спосіб побудови формальних оцінок якості цифрових оригіналів залежно від їх рівня шуму і розмиття. Спосіб заснований на застосуванні лінгвістичних змінних, для яких знайдені області визначення і області значення. Побудовано графіки функцій належності для цих змінних. Все це дозволяє автоматизувати однотипну обробку великої кількості оригіналів для видання. 


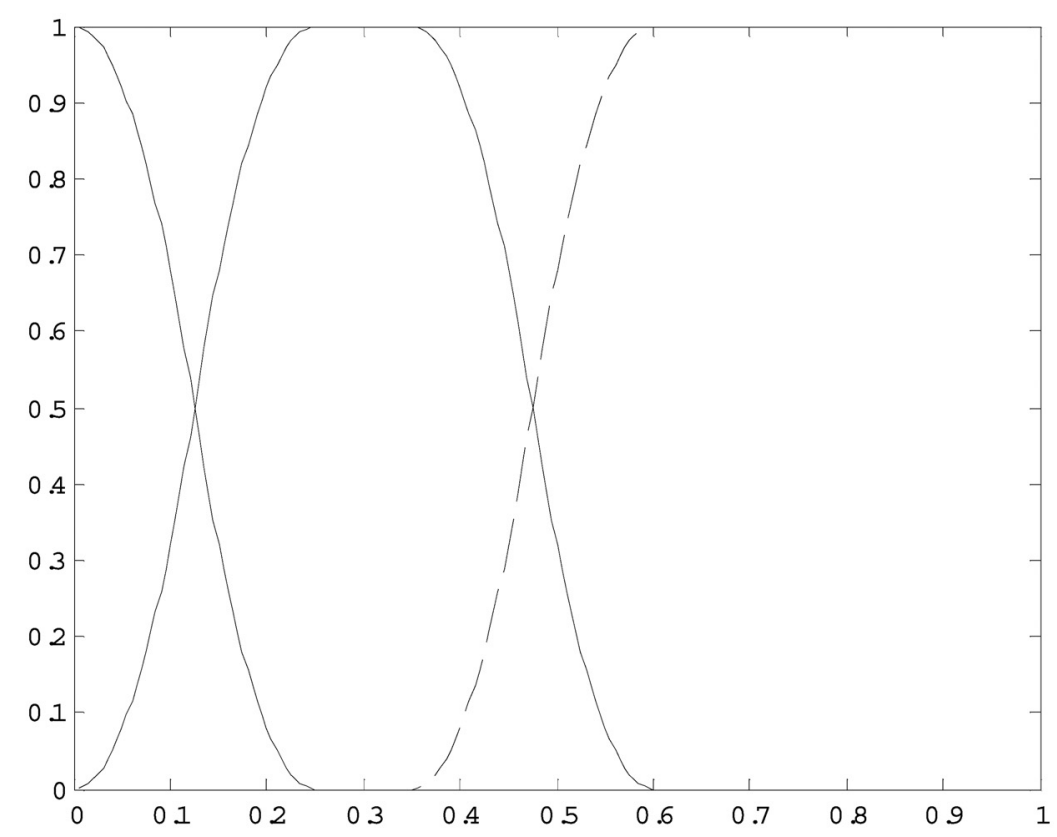

Рис. 4. Графіки функцій приналежності для розмитих зображень після апроксимації

\section{Список використаної літератури}

1. Подготовка иллюстративной информации для полиграфии [Электронный ресурс]. - Режим доступа : www/URL : http://www.compuart.ru/article.aspx?id=9101\&iid=381. -20.09 .2013 г. - Загл. с экрана.

2. Маргулис Д. Photoshop для профессионалов. Классическое руководство по цветокоррекции. [Текст] / Д. Маргулис. - М. : 000 «Интерсофтмарк», 2003. - 464 с.

3. Монич Ю. И. Оценки качества для анализа цифровых изображений [Текст] / Ю. И. Монич, В. В. Старовойтов // Искусственный интеллект. 2008. - № 4. - С. 376-386.

4. Методы оценивания изображений [Электронный ресурс]. - Режим доступа : www/URL : http://www.conf-ulstu.ru/dsp_6.php. - 28.05.2007 г. Загл. с экрана.

5. Гонсалес Р. Цифровая обработка изображений [Текст] / Р. Гонсалес. - М. : ТЕХНОСФЕРАМ, 2005. - 1071 с.

6. Заде Л. А. Понятие лингвистической переменной и его применение к принятию приближенных решений [Текст] / Л. А. Заде. - М. : МИР-М, 1976. -167 c.

7. Яхъяева Г. Э. Нечеткие множества и нейронные сети [Текст] / Г. Э. Яхъяева. - М. : Интернет-Университет Информационных технологий; БИНОМ. Лаборатория знаний, 2006. - 316 с.

8. Визуальный шум цифровых камер [Электронный ресурс]. - Режим доступа : www/URL : http://www.cambridgeincolour.com/ru/tutorials/imagenoise-2.htm. - 18.08.2013 г. - Загл. с экрана.

9. Джарратано Дж. Экспертные системы : принципы разработки и программирование [Текст] / Дж. Джарратано, Г. Райли : Пер. с англ. - М. : ООО «И.Д. Вильямс», 2007. - 1152 с. 
10. Попова А. А. Формирование набора тестовых изображений для определения функций принадлежности по степени зашумленности [Текст] / А. А. Попова // Состояние, достижения и перспективы информационных систем и технологий, 18.04.2013 г. : тез. науч.-техн. конф. - Одесса : OHAXT, 2013. - C. 106.

11. Попова А. А. Формализация описания дефектов на изображении при помощи лингвистической переменной и построения функции принадлежности [Текст] / А. А. Попова // Радиоэлектроника и молодежь в 21 веке, 21.04.2013 : тез. докл. - Харьков : ХНУРЭ, 2013. - С. 478.

12. Tai Shen-Chuan. A Fast Method For Image Noise Estimation Using Laplacian Operator and Adaptive Edge Detection [Text] / Shen-Chuan Tai, ShihMing Yang // ISCCSP. - 2008. - C. 1077-1081.

13. Crete F. The Blur Effect : Perception and Estimation with a New NoReference Perceptual Blur Metric [Text] / F. Crete, T. Dolmiere // SPIE Electronic Imaging Symposium Conf Human Vision. - 2007. - $11 \mathrm{c}$.

\section{References}

1. Podgotovka illjustrativnoj informacii dlja poligrafii [Jelektronnyj resurs]. Rezhim dostupa : www/URL : http://www.compuart.ru/article.aspx?id= 9101\&iid=381. -20.09 .2013 g. - Zagl. s jekrana.

2. Margulis D. Photoshop dlja professionalov. Klassicheskoe rukovodstvo po cvetokorrekcii. [Tekst] / D. Margulis. - M. : 000 «Intersoftmark», 2003. $464 \mathrm{~s}$.

3. Monich Ju. I. Ocenki kachestva dlja analiza cifrovyh izobrazhenij [Tekst] / Ju. I. Monich, V. V. Starovojtov // Iskusstvennyj intellekt. - 2008. - № 4. S. $376-386$.

4. Metody ocenivanija izobrazhenij [Jelektronnyj resurs]. - Rezhim dostupa : www/URL : http://www.conf-ulstu.ru/dsp_6.php. - 28.05.2007 g. - Zagl. s jekrana.

5. Gonsales R. Cifrovaja obrabotka izobrazhenij [Tekst] / R. Gonsales. - M. : TEHNOSFERA M, 2005. - 1071s.

6. Zade L. A. Ponjatie lingvisticheskoj peremennoj i ego primenenie k prinjatiju priblizhennyh reshenij [Tekst] / L. A. Zade. - M. : MIR-M, 1976. - $167 \mathrm{~s}$.

7. Jahjaeva G. Je. Nechetkie mnozhestva i nejronnye seti [Tekst] / G. Je. Jahjaeva. - M. : Internet-Universitet Informacionnyh tehnologij; BINOM. Laboratorija znanij, 2006. - $316 \mathrm{~s}$.

8. Vizual'nyj shum cifrovyh kamer [Jelektronnyj resurs]. - Rezhim dostupa : www/URL : http://www.cambridgeincolour.com/ru/tutorials/image-noise2.htm. - 18.08.2013 g. - Zagl. s jekrana.

9. Dzharratano Dzh. Jekspertnye sistemy : principy razrabotki i programmirovanie [Tekst] / Dzh. Dzharratano, G. Rajli : Per. s angl. - M. : OOO «l.D. Vil'jams», 2007. - 1152 s.

10. Popova A. A. Formirovanie nabora testovyh izobrazhenij dlja opredelenija funkcij prinadlezhnosti po stepeni zashumlennosti [Tekst] / A. A. Popova // Sostojanie, dostizhenija i perspektivy informacionnyh sistem i tehnologij, 18.04.2013 g. : tez. nauch.-tehn. konf. - Odessa : ONAHT, 2013. - S. 106.

11. Popova A. A. Formalizacija opisanija defektov na izobrazhenii pri pomoshhi lingvisticheskoj peremennoj i postroenija funkcii prinadlezhnosti [Tekst] / A. A. Popova // Radiojelektronika i molodezh' v 21 veke, 21.04.2013: tez. dokl. - Har'kov : HNURJe, 2013. - S. 478.

12. Tai Shen-Chuan. A Fast Method For Image Noise Estimation Using Laplacian Operator and Adaptive Edge Detection [Text] / Shen-Chuan Tai, ShihMing Yang // ISCCSP. - 2008. - C. 1077-1081. 
13. Crete F. The Blur Effect : Perception and Estimation with a New NoReference Perceptual Blur Metric [Text] / F. Crete, T. Dolmiere // SPIE Electronic Imaging Symposium Conf Human Vision. - 2007. - 11 c.

В статье рассмотрены вопросы, связанные с автоматизацией обработки пакетов изображений. Особенностью работы является способ оценивания качества цифровых оригиналов, основанный на использовании лингвистических переменных.

Ключевые слова: цифровые изображения, шум, размытие, лингвистическая переменная, функция принадлежности.

The article describes the aspects related to the automation of image packages processing. Feature of the work is a way of digital originals quality evaluating, based on the use of linguistic variables.

Keywords: digital images, noise, blur, linguistic variable, the membership function.

\section{Рецензент - І. В. Левикін, к.т.н.,} доцент, ХНУРЕ

Надійшла до редакції 18.08.14 